\title{
Social Annotation Enabling Collaboration for Open Learning
}

Jeremiah H. Kalir

University of Colorado Denver

Email: remi.kalir@ucdenver.edu

ORCID: 0000-0003-2302-7989

Twitter:@remikalir 


\title{
Social annotation enabling collaboration for open learning
}

\section{Jeremiah H. Kalir.}

Learning Design \& Technology, University of Colorado Denver, Denver, Colorado, 80204, United States

\begin{abstract}
Collaboration is a conceptually ambiguous aspect of open education. Given inconsistent discussion about collaboration in the open education literature, this article suggests collaboration be defined and studied as a distinct open educational practice. A theoretical stance from the discipline of computer-supported collaborative learning helps conceptualize collaboration as processes of intersubjective meaning-making. Social annotation is then presented as a genre of learning technology that can productively enable group collaboration and shared meaningmaking. After introducing an open learning project utilizing social annotation for group dialogue, analysis of interview and annotation data details how social annotation enabled three group-level epistemic expressions delineating collaboration as intersubjective meaning-making and as an open educational practice. A summative discussion considers how the social life of documents encourages collaboration, why attention to epistemic expression is a productive means of articulating open learning, and how to extend the study of collaboration as an open educational practice.
\end{abstract}

Keywords: annotation; collaboration; computer-supported collaborative learning; social design experiment; open educational practices (OEP)

\section{Introduction}

It is promising and problematic that the term open — when appended to discussions of educational resources (OER), educational practices (OEP), learning technologies, scholarship, networks, and more - remains linguistically flexible and accommodating of circumstance. Depending upon the context and conversation, "fifty shades of open" (Pomerantz \& Peek, 2016) may function reflexively, as open modulates from noun to adjective to verb, recursively underscoring a dogged openness to interpretation. Within the field of education, open persists as the subjective yet substantive catalyst provoking and muddying responses to Cronin and MacLaren's (2018) question: “Is open education a slogan or a philosophy, a metaphor, model, or

•Email: remi.kalir@ucdenver.edu 
movement?" (p. 127). Whatever this term may be or become, for those who study, facilitate, and advocate on behalf of open education this overtly amenable dynamic is not mere semantic inconvenience. Consider divergence among what counts as OEP and related efforts like "open pedagogy" (DeRosa \& Jhangiani, 2017; Stagg, 2017). This variance makes clear how the design, utility, and import of scholarly inquiry and educational programming may either suffer from an inability to point toward consensus or, alternatively, may flourish thanks to such diversity; or, Pomerantz and Peek (2016) conclude, "More phraseological neologisms will be coined using the word 'open.' As the word 'open' is used more, it will inevitably be used in new, and sometimes confusing, ways" (par. 75). In light of the state of the field — an acute moment emphasized by this special issue - this study was motivated by a need to discuss, examine, and define a somewhat opaque yet inclusive learning process often mentioned in tandem with OEP: collaboration.

Are OEP, whatever those practices comprise, collaborative? Or is collaboration one among many OEP? And in what respects has collaboration been conceptualized and studied as more than a catchall term associated with myriad open education topics? Recent literature reviews about OEP (Cronin \& MacLaren, 2018; Koseoglu \& Bozkurt 2018) and surveys of open education antecedents and the open landscape (Weller et al., 2018) suggest either explicitly or tacitly that the practices of open education — inclusive of research and pedagogy and spanning varied scholarly activities from networking to data-sharing - are somehow and in some way relevant to collaboration. Nonetheless, it is unsurprising yet unfortunate to observe that the idea of collaboration, much like the many shades of open (Pomerantz \& Peek, 2016), remains a conceptually ambiguous and understudied aspect of open education. 
How have open education scholars and practitioners discussed collaboration? Over a decade ago, the Cape Town Open Education Declaration (2007) suggested that collaborative, flexible learning was enabled by open technologies. This document noted that educational practices were built around collaboration and related concepts like discovery and knowledge creation, suggesting collaboration is among a select set of foundational qualities undergirding open education. Initial definitions of OEP, as in Ehlers (2011), framed collaborative practice as "essentially represent[ing]" (p. 6) the activities of resource sharing, participatory pedagogy, and peer-supported learning. Similarly, Cronin's (2017) definition of OEP pairs “collaborative practices" with both the "creation, use, and reuse of OER" and a broad repertoire of participatory "pedagogical practices" (p. 18) that attend to power relations, social inequalities, and institutional constraints. Collaboration and collaborative practices are also associated with open teaching (Couros, 2010) and open pedagogy (Hegarty, 2015), as with DeRosa and Jhangiani's (2017) discussion of how OEP informs the adoption of open pedagogy via collaborative activities like remixing or creating OER and facilitating student-created learning environments.

While the previously cited scholarship is not an exhaustive review of the open education literature, the sample demonstrates a need to define the wide-ranging and, at times, diffuse relationship between OEP and collaboration. In response, this article aims to define collaboration through reference to the learning sciences literature and, further, to describe an example of collaboration in open education that may be of use to other researchers, practitioners, and designers interested in demarcating and then pushing the boundaries of OEP. I advance this research agenda by turning toward theories of collaboration offered by the discipline of computer-supported collaborative learning (CSCL). The next section presents foundational perspectives on collaboration, with an emphasis on collaborative learning as intersubjective 
meaning-making (Suthers, 2006). Then, as a means of situating and illustrating this stance toward collaboration, I introduce social annotation (SA) as a genre of learning technology that exemplifies an open approach to intersubjective meaning-making. An open CSCL initiative, the Marginal Syllabus, is introduced with evidence from multiple data sources analyzed to demonstrate how SA enables collaboration through three coordinated epistemic expressions. Finally, my summative discussion addresses implications and future directions for the study of collaboration in open education.

\section{Conceptualizing collaboration}

Collaboration may be broadly understood as a social contract that is distinguishable from cooperative activity (Dillenbourg, 1999). Specifically, collaboration is neither a presumed attribute of shared presence, whether such presence is bounded by a classroom or online forum, nor is collaboration synonymous with all joint activity. Many cooperative learning tasks among groups, particularly in formal school settings, are prescriptive routines that eschew conflict, negotiation, and motivation endemic to the work of teams (Kirshner \& Erkens, 2013). Rather, creating the conditions for—and subsequently studying—collaboration requires learners to establish shared goals and sustain a problem space whereby common understandings guide collective negotiation, meaning-making, and other group cognition processes (Enyedy \& Stevens, 2006). While maintaining a joint problem space, learners must communicate with one another in order to collaborate. Yet not every conversation, whether mediated by spoken or written language, supports collaboration. CSCL researchers suggest a joint problem space encourages learners to productively communicate by externalizing and making visible their thinking, and by sharing and elaborating, transforming ideas, and also integrating their interactions into a group's shared knowledge (Stahl, 2017). In other words, collaboration is the 
organization of group communication into a new substance (Dillenbourg, 2005) that is then used to co-construct knowledge (e.g., Slotta \& Najafi, 2013).

Within this conceptualization of collaboration, Suthers (2006) has argued for a radically interactional epistemology that frames collaborative learning as a process of intersubjective meaning-making. This stance toward collaboration is predicated upon attention to communitylevel interactions of agreement, disagreement, and synthesis that are fundamentally participatory and mutually constituted among individuals, mediating technologies, and authentic social contexts. Collaboration, in this respect, is the study of practices that help to accomplish intersubjective meaning-making, or "how people in groups make sense of situations and each other" (p. 321). Intersubjective meaning-making occurs when people jointly contribute to related interpretations of a common activity through coordinated epistemic expressions that may include commentary, questions, explanations, expressions of attitude and affect, evidence-based arguments, and the presentation and re-presentation of ideas necessary for knowledge construction. Collaboration as intersubjective meaning-making is a conceptual stance that has provided insight about the ways in which middle school students participate in mathematical discourse (Nathan et al., 2007), how high school students read together online (Kiili et al., 2012), and how graduate students co-author research (Lin \& Kelsey, 2009). Suthers' (2006) conceptualization echoes a longstanding focus within CSCL regarding how shared meaning develops through learners" "continued attempt[s] to construct and maintain a shared conception of a problem" (Roschelle \& Teasley, 1995, p. 70). I extend a congruous line of inquiry by examining collaboration — and collaborative learning — as the interactive and intersubjective processes of meaning-making enabled at a group level by the participatory and open practices of SA. 


\section{SA enabling collaboration}

SA is a genre of learning technology that affords people the ability to annotate, or mark up with interactive commentary and other forms of digital media, resources for the social purposes of information sharing and knowledge construction (Novak et al., 2012). Given growth in SA use for learning in both K-12 and university settings (e.g., Sprouse, 2018), and among openly networked global networks (e.g., Kalir, 2018), it is important to note that SA does not necessarily afford collaborative learning. SA can encourage cooperative learning as with, for example, experts who annotate scientific literature in order to define terminology, clarify disciplinary methods, and emphasize the significance of research for novices (McCartney et al., 2018). Moreover, SA may be used to encourage, though with mixed measurable success, individual study (Winchell et al., 2018). Accordingly, when discussing SA in the context of collaborationand, as with this article, when framing SA as enabling collaborative learning through processes of intersubjective meaning-making - it is useful to name the qualities of SA that encourage groups to collaborate.

Multiple facets of SA bolster the conditions under which annotation enables collaboration and encourages intersubjective meaning-making among groups. First, SA enables collaboration when learners perceive and engage with texts as dialogical contexts. SA creates an anchored environment characterized by proximal and contextualized discussion (Gao et al., 2013) whereby complementary social interactions with and within the text-as-context (Kalir, 2019) help bound the problem space. In other words, the technical and social affordances of SA define texts as problem spaces that situate collaborative learning. Second, when groups communicate via SA, they produce various types of artifacts - inclusive of annotation content, metadata, and other digital representations like learning analytics — that may be useful when constructing new 
knowledge. Both the technical features of SA tools, especially those aligned to open standards and open web principles (Whaley, 2017), alongside pedagogical guidelines for SA use, can together facilitate the creation of digital and ideational artifacts generative of new knowledge (Chen, 2019). Third, productive group discourse is possible as SA encourages learners to easily share their intersubjective interpretations. Whether through creative forms of multimodal selfexpression or through shared digital literacy practices (Kalir \& Garcia, 2019), SA provisions learners with multiple entry points for expansive and meaningful contributions to group activity. Collectively, these qualities - texts as problem spaces for sustained interaction, the production of artifacts to guide knowledge construction, and the ease with which interpretations are shared among a group — foreground how SA can catalyze processes of intersubjective meaning-making.

Given divergent reference to collaboration in the open education literature, I previously suggested that it is advantageous to define collaboration as an OEP. To do so, I have drawn upon the discipline of CSCL to conceptualize collaboration as processes of intersubjective meaningmaking. Moreover, I have now introduced SA as a genre of learning technology that can productively enable such group collaboration. To further articulate relations among collaboration, SA, and OEP, I now introduce a case study of annotation use in open education that is guided by the question: How can SA enable collaboration as an OEP?

\section{Methodology: a case study of annotation as collaboration}

To demonstrate how SA can enable collaboration as an OEP, I present a qualitative case study of learner participation in a public, openly networked, and interest-driven project. This study focuses on how a group of educators has voluntarily contributed to the Marginal Syllabus (http://marginalsyllab.us). Since 2016, the Marginal Syllabus has sparked and sustained public conversation about educational equity. Thanks to sustained partnerships with educational 
organizations and leading education scholars (e.g., Mirra, 2018), the Marginal Syllabus has grown into a public CSCL initiative that uses SA to encourage shared dialogue about equity topics related to civic engagement, literacy, and learning (Kalir, 2019; Kalir \& Garcia, 2019). Iterations of multiple syllabi have helped clarify how the project's design principles advance a model of equity-oriented design in open education by leveraging open web technologies, fostering multi-stakeholder partnerships, engaging with and producing open content, and facilitating open approaches to professional learning (Kalir, 2018). This case study, which emerged from ongoing inquiry about the Marginal Syllabus as a social design experiment (Gutiérrez \& Jurow, 2016), is an effort to describe how such a project creates the conditions for educator collaboration as an open and professionally relevant practice.

The Marginal Syllabus has been described as an example of the social scholarship of teaching, or a means of publicly leveraging "the possibilities afforded by social media-enabled tools, platforms and communities of practice to enrich and expand the study and iterative refinement of teaching for learners and teachers alike" (Greenhow et al., 2019, p. 995). Similar to an online book club, Marginal Syllabus conversations occur because partner authors who have consented to have their scholarship made openly accessible for the purposes of public dialogue. Over a set period of time, typically 1 month, groups of educators from multiple disciplines and both K-12 and postsecondary settings gather together synchronously and asynchronously to read and discuss a focal text using the SA tool Hypothesis (http://web.hypothes.is). Figure 1 illustrates a representative Marginal Syllabus conversation. In this instance, an article about critical media literacy and racial injustice (Baker-Bell et al., 2017) served as the problem space for dialogue that elicited educator interpretation about ethical stances toward digital literacy, professional expertise, and equitable learning spaces (Kalir \& Dillon, 2020). 


11 of 23 The Stories They Tell: Mainstream
Media, Pedagogies of Healing, and
Critical Media LiteraCy
April Baker-Bell, Raven Jones Stanbrough, and Sakeena
Everett
Pedagogies of healing and critical media literacy are important, especially in the wake of racial
violence when mainstream media work to stigmatize, characterize, and marginalize Black youth
by projecting them as dangerous Others. In this article, we offer an overview of how mainstream
media reinscribe and reinforce white supremacy, which leads to anti-blackness. Next, we discuss
the impact that uncritical consumption of mainstream media narratives of Black people has on
media consumers and how Black youth use social media as counterspaces. We then theorize about
pedagogies of healing and critical media literacy as tools to encourage Black youth to investigate,
dismantle, and rewrite the damaging narratives. We conclude with sample lesson plans and a
discussion of how English educators have a responsibility to use our discipline to transform our
world and raise awareness of the crisis of racial injustice.
If you aren't careful, the newspapers will have you hating the people who are being
oppressed and loving the people who are doing the oppressing.
-Malcolm X, At The Audubon, 1964
Rather than seen as victims, Blackyouth are vilified, and viewed as suspicious, delinquent
or dangerous by mass media.

-Henry Giroux, The Fire This Time, 2015

W

Then we first began writing this article in October 2015, we were wit-

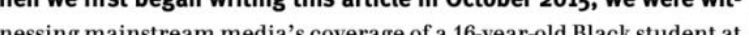

फ. Public $\vee \quad Q \uparrow_{\downarrow}<? 2 \vee$

ccantrill Mar 18, 2018

(3) Public

| who was assaulted in her math class

I'm just noticing now this mention that it was a math class where this happened. I'm not sure what to make if it really, and I don't want to over-make ... but/and I can't help but wonder about the connection.

My thinking about math education and the relationship to oppression/liberation is prompted by looking recently at the resources of the Youth

People's Project (such as the Flagway Game)

started by Bob Moses vis a vis the Algebra

Project.

http://www.typp.org/

Mission YPP uses Math Literacy Work to develop the abilities of elementary through high

school students to succeed in school and in life, and in doing so involves them in efforts to eliminate institutional obstacles to their success.

Vision YPP envisions a day when every young person - regardless of ethnicity, gender, or class - has access to a high quality education and the skills, attributes, and community support s/he needs to successfully meet the challenges of their generation.

\#marginalsyllabus "ED677

Hide replies (1)

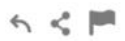

JonesGirl Apr 3, 2018

3 Public

Oh Wow! Thank you for this reference and for illuminating the connections you see with mathematical education and oppression/lib-

Figure 1. A representative Marginal Syllabus conversation showing source text-as-context with accompanying public layer of Hypothesis social annotation (source: Marginal Syllabus).

\section{Data sources and analysis}

This study of Marginal Syllabus participants "mak[ing] sense of situations and each other" (Suthers, 2006, p. 321) aimed to identify specific epistemic expressions enabled by SA that, as group-level interactions, define collaboration as an OEP. Syllabi annotated during the 2016-17, 2017-18, and 2018-19 academic years, and during the Summer of 2019, have provided over 250 educators with the opportunity to jointly contribute individual interpretations of meaning to over 30 scholarly texts as discursive problem spaces. Annotation conversations evidence groups coordinating shared practices, like educators critically questioning assumptions, providing 
exposition of ideas, evaluating claims, and participating in other forms of critical and digital literacy (Kalir \& Garcia, 2019). Given the breadth of Marginal Syllabus activity, this case study draws upon two data sources - educator interviews and annotations from a focal conversationin order to investigate processes of intersubjective meaning-making and substantiate evidencebased claims about collaboration as an OEP.

Interviews. The first data source featured in this case study is interviews with Marginal Syllabus participants (names are pseudonyms). Semi-structured interviews have been conducted on an ongoing basis with educators who have participated in at least one Marginal Syllabus conversation. Data for this case study were drawn from interviews with 27 educators who joined conversations during the 2017-18 Marginal Syllabus and, for some, continued to participate throughout the 2018-19 academic year. Following transcription and the removal of identifiable information, all interviews were inductively analyzed using descriptive coding methods (Saldaña, 2016) to identify how educators discussed participation in Marginal Syllabus conversations and how they perceived SA to enable collaboration and learning. Two researchers independently and descriptively coded interview excerpts related to collaboration, compared and discussed codes, and then iteratively refined a shared coding scheme in order to identify themes relevant to processes of intersubjective meaning-making.

Annotations. Because themes were first identified from educators' retrospective commentary (i.e., interviews asked about prior instances of, and perspectives on, collaboration), a second data source was needed to further illustrate what processes of coordinated interpretation looked like in educators' SA-enabled dialogue. Hypothesis SA data was collected by the research team from the first conversation of the 2018-19 Marginal Syllabus in which educators discussed pedagogical responses to "the intersections of healing, politics, and emotion in today's 
classrooms" (Garcia \& Dutro, 2018, p. 376). This focal conversation was selected for three reasons. First, prior studies (Kalir \& Dillon, 2020; Kalir \& Garcia, 2019) have examined patterns among educator participation in SA conversations from the 2016-17 and 2017-18 syllabi. Second, the selected conversation represents the average number of participants and volume of annotations associated with a typical conversation from any syllabi; in this instance, 28 educators authored 147 annotations, including 34 responsive threads, over 21 days of activity. Third, about half of the conversation participants (12) had previously participated in interviews, providing an opportunity to confirm or disconfirm if both Marginal Syllabus regulars and newcomers made sense of their discursive situation using similar epistemic expressions.

Annotation data was collected and analyzed using the CROWDLAAERS dashboard (“crowd layers"; http://crowdlaaers.org), a public tool that visualizes open Hypothesis data as learning analytics (Hypothesis' Terms of Service attribute a Creative Commons CC0 Public Domain Dedication to all public annotations; educators' Hypothesis usernames are not pseudonyms in this study, and minor edits have been made to quoted annotations). This dashboard for Capturing and Reporting Open Web Data for Learning Analytics, Annotation, and Education Researchers (CROWDLAAERS) is a public service that visualizes group—or crowd — discourse layers added via Hypothesis SA to online documents. In alignment with recent trends in CSCL research, the dashboard has been iteratively co-designed to report and visualize group-level social learning analytics (Shum \& Ferguson, 2012), such as processes that evidence social interaction (e.g., SA threads). Figure 2 is a screenshot of CROWDLAAERS visualizing SA-enabled educator interaction during the focal Marginal Syllabus conversation. Social learning analytics associated with 34 threads were examined by the researchers for evidence of themes related to educators' intersubjective meaning-making. 


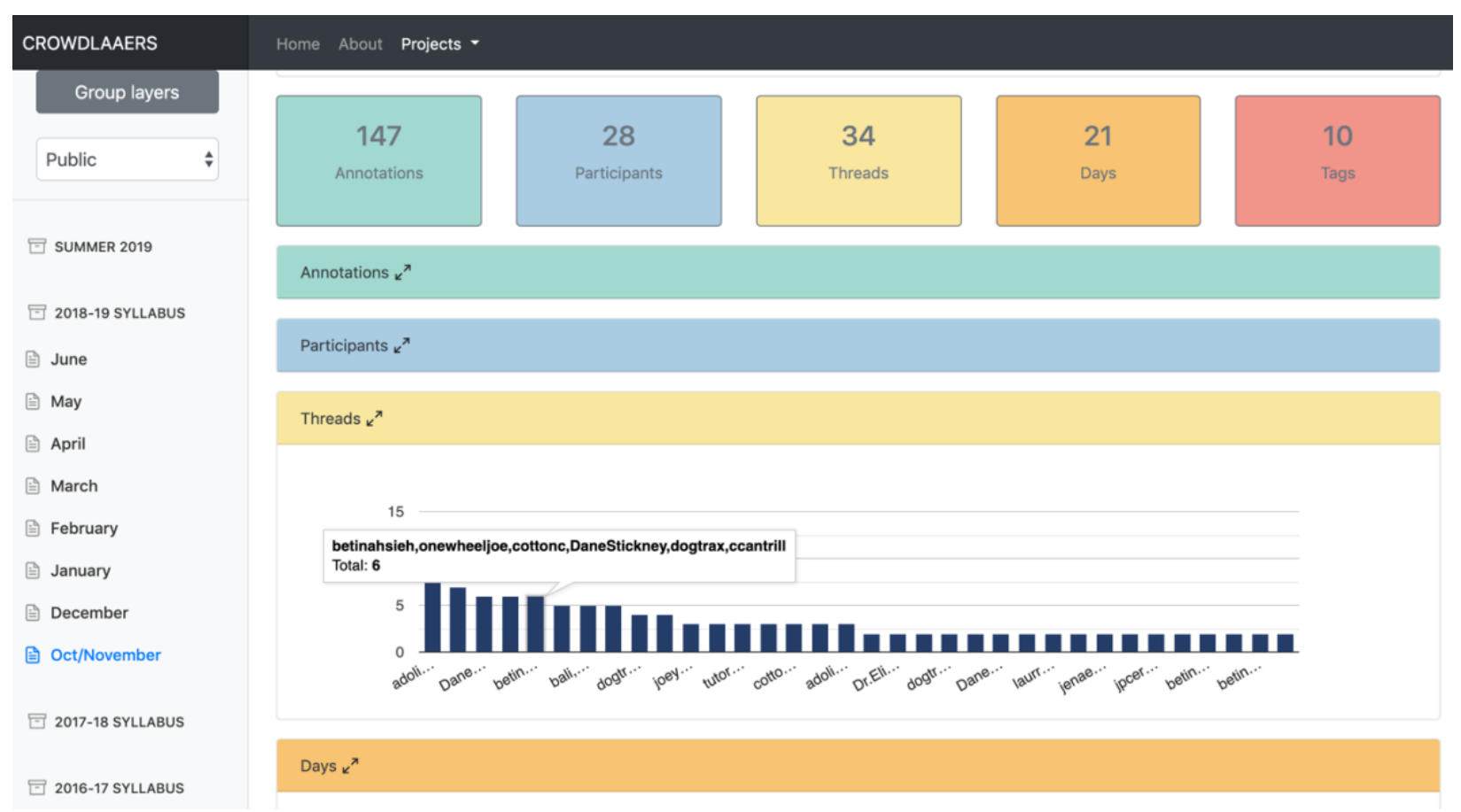

Figure 2. Screenshot of CROWDLAAERS visualizing SA-enabled educator interaction during the focal Marginal Syllabus conversation (source: CROWDLAAERS).

\section{Limitations}

As an exploratory investigation of collaboration as intersubjective meaning-making, this case study examined a single Marginal Syllabus conversation. The research design of future studies should detail how educators' coordinated epistemic expressions do, or do not, occur among multiple conversations. Further, analysis of interview data did not highlight challenges associated with educators' SA use or Marginal Syllabus participation. Finally, annotation data included in this case study were associated with discursive threads, comprising 114 of 147 annotations from the focal conversation. CROWDLAAERS could be used to examine the entire corpus to determine how all annotations, including those with no replies, may have contributed to group-level meaning-making processes. 


\section{Findings: epistemic expressions as open practice}

During Marginal Syllabus conversation, educators used SA to share individual interpretations of a text and make sense of a shared problem space. As educators communicated together using SA-enabled dialogue over time, individual interpretations became group-level and coordinated epistemic expressions. Analysis of interview and annotation data indicate three epistemic expressions were common to participants' intersubjective meaning-making processes and, consequently, defined collaboration as an OEP: contributing to group inquiry, establishing associative connections, and discerning multiple perspectives.

\section{Contributing to group inquiry}

Educators who participated in Marginal Syllabus conversations shared SA as public writing to expressly contribute to group inquiry and make their thinking visible to others. Joining a Marginal Syllabus conversation was perceived as an opportunity for "deep dives or deep investigations into particular topics" (Dominique), and, for Stacey, an occasion to "do some thinking alongside colleagues." Upon the start of a new annotation conversation, Kenneth noted an "immediate desire to share my ideas and engage with other ideas," a sentiment that echoed reflections on group activity in which "we are constantly in there adding, communicating with each other" (Sophia). Kallie was among multiple participants who commented upon how SA afforded more accessible and distributed cognition leading to group-level accomplishments: "How cool is it to get access to other people's critical thoughts and reflections on these readings? ... That process is how new ideas are born and how intellectual work happens." This communication as "intellectual work" echoes Dillenbourg's (2005) new substance mediating knowledge construction; or, as Bridgit described it, "We can build on one another's knowledge and all the brilliant things people bring to that [conversation] as long as we're online." 
The focal annotation conversation included instances in which group inquiry made accessible "critical thoughts" for participants to build upon "the brilliant things people bring" and facilitate a process by which "new ideas are born." In Garcia and Dutro's (2018) article, they observed: "The nuances of a 'safe space' for SEL [social and emotional learning] in our classrooms requires looking across social, political, and cultural factors for all members of a school community" (p. 378). This portion of the text was chosen as a problem space in which 10 participants shared interpretations that collectively contributed to group inquiry and meaningmaking. The following is excerpted from the 11 annotations comprising the discursive thread (the indentation of annotations mirrors Hypothesis' threaded comment structure):

adolid: One of the complexities of this is that teachers sometimes don't believe the academic space is where these conversations should occur, despite adoption of SEL approaches by a school; we have cultivated teachers who, because of pressures around test accountability, grades, and perceptions of traditional models of success, experience conflict around the heart and mind binary - school is for academics and thinking, while spaces outside of school are for nourishing the heart. Obviously we need to interrupt this stance to show how each feed the other.

bali: I was thinking while reading this part that even the notion of creating safe spaces is nuanced... what may seem like safe space for a teacher may not be safe for certain vulnerable populations. How do we remain sensitive to these? But I also hear you on how school neoliberal culture does not at all encourage this kind of thinking in the first place

jenaecohn: I really appreciate Maha's question here about how we determine which kinds of spaces are "safe" for some students and not for others. I'm also wondering, to this same end, how we help accommodate different forms of safety without dividing the classroom environment up or calling out individuals (especially if we're not sure they want to be called out).

cottonc: It may be helpful to look into work that advocates the creation of "brave spaces" rather than safe spaces... spaces that simultaneously challenge our students and recognize the inherent discomfort in many of these conversations, while also maintaining a sense of safety and openness. 
Contributions to group inquiry, in this thread, included critical thoughts about educators' professional dispositions and practices, questions that extended the dialogue ("How do we remain sensitive to these?"; bali) and considerations and suggestions about what counts as an educational safe space. In the unfolding knowledge construction process, it is cottonc's annotation that functions to both synthesize and present a new idea ("brave spaces") that honors the "conflict" and discomfort implied by adolid and jenaecohn's comments, and the safety and sensitivity that grounds bali's advocacy and critique.

\section{Establishing associative connections}

Educators who participated in the Marginal Syllabus established associative trails (Bush, 1945) as both a cognitive and socio-technical accomplishment, and made use of these connections to specify the relatedness of ideas, resources, and people. Lester remarked that annotation conversation symbolized the "idea of connected texts together," a sentiment similar to Teresa's assessment that group activity in the Marginal Syllabus is "a focused exploration of a core text but then with the opportunity to connect to other ideas and the fact that you can do that openly." Associative connections were readily contributed to Marginal Syllabus conversations because, as Octavia observed, "Everything is interconnected, so you can wind up making one text relate to a million different things that were going on in society or in art, in culture." In addition to interestbased associations, some educators appreciated how the technical affordances of SA helped them maintain professionally relevant networks: "By openly annotating the web, it allows me to connect with people in my professional learning network, which is a global network" (Yvette). Interview data suggest educators' ability to collectively establish associative connections was generative of socially constructed meaning; as Danielle recounted, "If we can at least start from the same place and bridge from there... it can produce a meaningful exchange." 
A number of threads from the focal conversation evidenced the value of connections among "people in my professional learning network" alongside acknowledgement that connections "can produce a meaningful exchange." For example, two words that appeared in a section heading of Garcia and Dutro’s (2018) article_-“Testimony, Witness” (p. 378)—were highlighted and annotated by four participants whose exchange transparently reflected upon their pedagogy and professional contexts, the promise and limitations of certain teaching practices, as well as a prior Marginal Syllabus conversation that featured a related story.

jgmac1106: I find giving my students a domain and the freedom to write leads to healing through words. To data [sic] I have had students discuss their journey with dating violence, bulimia, and addiction. Looking back as I write this, however, it seems the ability to engage in healing writing is an engendered practice. Not sure I have had any students who identify as male take a risk in their healing.

onewheeljoe: I appreciate the reflection here while you share your practice. It certainly encourages others to do the same, and probably makes them feel safe to admit if they don't know how to begin.

DaneStickney: Interesting point on gender. I taught middle-school writing in north Denver. One of the most powerful pieces was a male student reflecting on his father's death. But, to your point, the ratio of those that took the biggest emotional risk skewed heavily toward female students.

ccantrill: Appreciating these notices/insights from your classrooms and they made me think that this annotatable chapter from Bronwyn LaMay's book might be of interest.

This thread began with jgmac1106 establishing associative connections to interrelated professional and political contexts as he assessed how his students had, and had not, authored "healing writing" for the purposes of a personal wellbeing "journey." onewheeljoe's acknowledgement, a form of interpersonal connection, is then echoed by DaneStickney, who offered associative connections to similar pedagogical practices and observations about student writing, "emotional risk," and gender. Finally, ccantrill voiced a unifying comment that honored common "notices/insights from your classrooms" while also recommending that participants 
further pursue their interests by engaging with a relevant article previously featured in the Marginal Syllabus. Educators established associative connections throughout this thread that broadened shared meaning about relationships among literacy, healing, learning, and identity.

\section{Discerning multiple perspectives}

A third epistemic expression characteristic of educators' Marginal Syllabus participation was a process of discernment through which annotation elicited multiple perspectives on a given topic and provoked awareness, scrutiny, or conceptual change. For some educators, like Dominique, sharing and encountering diverse perspectives informed cycles of comprehension: “They’ve added their thoughts on it, and then I will go back and review that again and, perhaps, that opens another window, for me, in terms of understanding that document." Likewise, Oscar described his ongoing participation from one conversation to the next as, "I'm approaching the writing from 'How might I address some of the ideas, questions, thoughts of those that I was annotating with on the Web?"' Processes of discernment required, in Karine's assessment, vulnerability: "It's okay to play with ideas and be wrong and go through a process and learn new things and be taken to different places, so in that sense I think it's extremely valuable." Whether discernment of multiple perspectives led to critique or consensus, such interactions were frequently oriented toward change: "The two of you could maybe work together to build on that or to push back against it and change it" (Kallie). Victor echoed this sentiment, remarking how through regular annotation dialogue "the broader range of those perspectives can infiltrate our own thinking."

Returning once more to the focal conversation, Garcia and Dutro's (2018) discussion of healing suggested that recent interest in social and emotional learning reflects a broader question that educators and schools must grapple with: "What does it mean to matter (or \#matter) in this world?" (p. 378). When collectively reading “\#matter," educators used SA to first name, and 
then affirm, make sense of, and extend multiple perspectives relevant to this term. The following exchange among five participants “opens another window" (Dominique) for the group's shared comprehension and, ultimately, invites educators to "be taken to different places" (Karine).

DaneStickney: Interesting little move here.

onewheeljoe: What does this move mean to you? I confess to searching to see if \#matter has its own significance in the world of Twitter and memes, but I've decided it must be a reference to BLM. (I could ask Antero for clarification, but it is out of his hands now, and I'm curious how others read this.)

DaneStickney: I definitely saw it as a Black Lives Matter reference.

tayken: That was my immediate interpretation as well (BLM)

ccantrill: I wasn't sure either. Thanks for asking.

Sarah $L W$ : it also reminds me that the broader conversation is taking place across spaces and modalities

What may appear to be a brief exchange concerned with the definition of a term reveals, rather, the role of curiosity and vulnerability in helping a group to discern, and find value in, multiple perspectives. DaneStickney's indication of interest led both onewheeljoe and ccantrill to publicly acknowledge uncertainty and appreciation for the distributed sense-making process. As the thread developed, both DaneStickney and tayken named their interpretations to build consensus around a particular perspective. In the thread's final contribution, SarahLW offered a complementary yet new perspective on the "spaces and modalities" that situate "the broader conversation" about whose lives matter. This example illustrates how individual attempts to read a word can be transformed by SA into shared understandings of the world, with both literal and social meaning accomplished through group-level observations, questions, and concurrence. 


\section{Discussion and conclusion}

This study has modeled for open education researchers and advocates one approach to defining collaboration in open learning. For collaboration to be understood as more than a vague or inconsistent descriptor, the open education literature will benefit from studies-like this onethat offer a theoretically grounded definition of collaboration, that present an open learning context situating people's joint activity, and that make empirical claims about the specific qualities that comprise collaboration as open learning. This article first defined collaboration as processes of intersubjective meaning-making, then introduced the Marginal Syllabus as an open learning project utilizing SA technology for such meaning-making, and detailed how SA enabled three group-level epistemic expressions delineating collaboration as an OEP. This summative discussion now considers how open initiatives like the Marginal Syllabus can amplify the social life of documents (Brown \& Duguid, 1996) as valuable sites for open collaboration, why attention to epistemic expression is a productive means of further articulating open learning, and how to usefully extend the study of collaboration as an OEP.

As emphasized throughout this study, it is productive to investigate how people learnand how they collaborate - in open education contexts by viewing OEP through a theoretical lens. An open project like the Marginal Syllabus intentionally aligns pedagogical, social, and technological elements of CSCL (Kirschner \& Erkens, 2013) to scaffold the ways in which educators encounter and interact with texts as dialogical contexts and, consequently, build intersubjective meaning about educational equity topics. Within the Marginal Syllabus, as with other annotation-enabled learning environments (e.g., Gao et al., 2013), academic literature not only functions as a shared problem space; the texts situating annotation conversation evidence a socially constructed site of personal, professional, and also political relevance. This dynamic 
echoes Brown and Duguid (1996), who assert: "Providing a shared context for constructing meaning, documents are the beginning rather than the end of the process of negotiation" (par. 32). Indeed, Marginal Syllabus participant Kenneth reported perceiving texts as contexts for social meaning-making, observing: "I see an article, and I immediately think about it in a social context." Moreover, the preceding process of negotiation can be encouraged by educators like Sophia who described texts as "a living, organic, breathing community;" she recalled her experience in Marginal Syllabus conversations as "trying to make every text contingent, and the contingencies have to do with the lived experiences of people encountering that text." In order to explore collaboration as an OEP, it was necessary for this study to conceive of texts as contexts whose social life first situates and then sparks meaning-making among groups. Locating new sites for open collaboration at the intersection of educational resources, networks, and meaningmaking processes may be a useful strategy for other open education researchers interested in how OEP emerges from technology-mediated communication—as with dialogue enabled by SA.

When groups of educators used SA to publicly participate in Marginal Syllabus conversations, individual interpretations of equity-oriented educational scholarship were transformed into collective sense-making substance (Dillenbourg, 2005). Specifically, educators contributed to group inquiry, established associative connections, and discerned multiple perspectives. The three epistemic expressions identified in this study are an exploratory yet evidence-based attempt to describe what collaboration can look like among learners who voluntarily participate in a technology-rich and open learning environment across space and time. Interviews with additional Marginal Syllabus participants and further investigation of other annotation conversations, whether as a part of the Marginal Syllabus or among other SA-enabled projects, may reveal similar or dissimilar group-level epistemic expressions that expand upon 
this portrayal of collaboration as an OEP. Evidence has accumulated that openly networked SA enables sharing, negotiation, and synthesis, thereby motivating knowledge construction (Chen, 2019), group comprehension (Sprouse, 2018), and civic literacy (Kalir \& Garcia, 2019). This study contributes to the SA literature by suggesting group-level epistemic expressions are a productive focus for clarifying and detailing what comprises collaboration and counts as OEP in open learning contexts.

In order to advance the study of collaboration as an OEP, this article has featured both a conceptual argument and a case study in the hopes of encouraging open learning advocates to likewise define with nuance what collaboration and collaborative learning can mean in the context of open education. Though to be clear, future studies investigating the relationship between collaboration and OEP need not draw explicitly upon the learning sciences, a discipline like CSCL, or a definition of collaboration that frames how participants come to make sense of a shared problem space and one another. Aspects of open pedagogy may indeed be collaborative (DeRosa \& Jhangiani, 2017), just as the cooperative acts of sharing networked scholarship (Veletsianos \& Kimmons, 2012) may be perceived as a participatory activity. Nevertheless, future studies of open practices—like collaboration — will benefit both open education scholarship and programming when inquiry into the complexities of OEP is theoretically grounded and defined by processes of group learning across scales and settings. 


\section{Acknowledgements}

Thank you to all Marginal Syllabus participants and partners, including the National Writing Project, the National Council of Teachers of English, and Hypothesis.

\section{Disclosure statement}

No potential conflict of interest was declared by the author.

\section{Notes on contributor}

Jeremiah H. Kalir is assistant professor of learning design and technology at the University of Colorado Denver and studies how social annotation enables collaborative, open, and equitable learning.

ORCID

Jeremiah H. Kalir https://orcid.org/0000-0003-2302-7989

\section{Data availability statement}

Hypothesis data reported using CROWDLAAERS is available at crowdlaaers.org.

\section{References}

Baker-Bell, A., Stanbrough, R., \& Everett, S. (2017). The stories they tell: Mainstream media, pedagogies of healing, and critical media literacy. English Education, 49(2), 130-152. https://secure.ncte.org/library/NCTEFiles/Resources/Journals/EE/0492jan2017/EE0492Stories.pdf

Brown, J. S., \& Duguid, P. (1996). The social life of documents. First Monday, 1(1). https://firstmonday.org/article/view/466/387

Bush, V. (1945). As we may think. The Atlantic Monthly, 176(1), 101-108. https://www.theatlantic.com/magazine/archive/1945/07/as-we-may-think/303881/ 
Cape Town Open Education Declaration. (2007). The Cape Town Open Education Declaration: Unlocking the promise of open education. http://www.capetowndeclaration.org/read-thedeclaration

Chen, B. (2019). Designing for networked collaborative discourse: An UnLMS approach. TechTrends, 63(2), 194-201. https://doi.org/10.1007/s11528-018-0284-7

Couros, A. (2010). Developing personal learning networks for open and social learning. In G. Veletsianos (Ed.), Emerging technologies in distance education (pp. 109-127). AU Press. https://www.aupress.ca/books/120177-emerging-technologies-in-distance-education/

Cronin, C. (2017). Openness and praxis: Exploring the use of open educational practices in higher education. The International Review of Research in Open and Distributed Learning, 18(5), 2-21 . https://doi.org/10.19173/irrodl.v18i5.3096

Cronin, C., \& MacLaren, I. (2018). Conceptualising OEP: A review of theoretical and empirical literature in open educational practices. Open Praxis, 10(2), 127-143. https://doi.org/10.5944/openpraxis.10.2.825

DeRosa, R., \& Jhangiani, R. (2017). Open pedagogy. In E. Mays (Ed.), A guide to making open textbooks with students (pp. 6-21). Rebus Community.

Dillenbourg, P. (1999). What do you mean by collaborative learning? In P. Dillenbourg (Ed.), Collaborative learning: Cognitive and computational approaches (pp. 1-19). Elsevier. https://telearn.archives-ouvertes.fr/hal-00190240/document

Dillenbourg, P. (2005). Designing biases that augment socio-cognitive interactions. In R. Bromme, F. Hesse, \& H. Spada (Eds.), Barriers and biases in computer mediated knowledge communication (pp. 243-264). Springer. https://doi.org/10.1007/0-38724319-4_11 
Ehlers, U.-D. (2011). Extending the territory: From open educational resources to open educational practices. Journal of Open, Flexible, and Distance Learning, 15(2), 1-10. http://www.jofdl.nz/index.php/JOFDL/article/view/64/46

Enyedy, N., \& Stevens, R. (2006). Analyzing collaboration. In K. Sawyer (Ed.), The Cambridge handbook of the learning sciences (pp. 191-212). Cambridge University Press. https://doi.org/10.1017/cbo9781139519526.013

Gao, F., Zhang, T., \& Franklin, T. (2013). Designing asynchronous online discussion environments: Recent progress and possible future directions. British Journal of Educational Technology, 44(3), 469-483. https://doi.org/10.1111/j.1467$8535.2012 .01330 . x$

Garcia, A., \& Dutro, E. (2018). Electing to heal: Trauma, healing, and politics in classrooms. English Education, 50(4), 375-383. https://library.ncte.org/journals/ee/issues/v50-4

Greenhow, C., Gleason, B., \& Staudt Willet, K. B. (2019). Social scholarship revisited: Changing scholarly practices in the age of social media. British Journal of Educational Technology, 50(3), 987-1004. https://doi.org/10.1111/bjet.12772

Gutiérrez, K., \& Jurow, A. S. (2016). Social design experiments: Toward equity by design. Journal of the Learning Sciences, 25(4), 565-598. https://doi.org/10.1080/10508406.2016.1204548

Hegarty, B. (2015). Attributes of open pedagogy: A model for using open educational resources. Educational Technology, 55(4), 3-13. https://www.jstor.org/stable/44430383

Kalir, J. (2018). Equity-oriented design in open education. International Journal of Information and Learning Technology, 35(5), 357-367. https://doi.org/10.1108/ijilt-06-2018-0070 
Kalir, J. (2019). Open web annotation as collaborative learning. First Monday, 24(6). https://firstmonday.org/ojs/index.php/fm/article/view/9318/7809

Kalir, J., \& Dillon, J. (2020). Educators discussing ethics, equity, and literacy through collaborative annotation. In K. H. Turner (Ed.), The ethics of digital literacy: Developing knowledge and skills across grade levels (pp. 131-142). Rowman \& Littlefield.

Kalir, J., \& Garcia, A. (2019). Civic writing on digital walls. Journal of Literacy Research, 51(4), 420-443. https://doi.org/10.1177/1086296x19877208

Kiili, C., Laurinen, L., Marttunen, M., \& Leu, D. J. (2012). Working on understanding during collaborative online reading. Journal of Literacy Research, 44(4), 448-483. https://doi.org/10.1177/1086296x12457166

Kirschner, P. A., \& Erkens, G. (2013). Toward a framework for CSCL research. Educational Psychologist, 48(1), 1-8. https://doi.org/10.1080/00461520.2012.750227

Koseoglu, S., \& Bozkurt, A. (2018). An exploratory literature review on open educational practices. Distance Education, 39(4), 441-461. https://doi.org/10.1080/01587919.2018.1520042

Lin, H., \& Kelsey, K. D. (2009). Building a networked environment in Wikis: The evolving phases of collaborative learning in a Wikibook project. Journal of Educational Computing Research, 40(2), 145-169. https://doi.org/10.2190/ec.40.2.a

McCartney, M., Childers, C., Baiduc, R., \& Barnicle, K. (2018). Annotated primary literature: A professional development opportunity in science communication for graduate students and postdocs. Journal of Microbiology \& Biology Education, 19, 1-11. https://dx.doi.org/10.1128\%2Fjmbe.v19i1.1439 
Mirra, N. (2018). Pursuing a commitment to public scholarship through the practice of annotation. The Assembly: A Journal for Public Scholarship on Education, 1. https://www.colorado.edu/journal/assembly/2018/12/12/pursuing-commitment-publicscholarship-through-practice-annotation

Nathan, M. J., Eilam, B., \& Kim, S. (2007). To disagree, we must also agree: How intersubjectivity structures and perpetuates discourse in a mathematics classroom. Journal of the Learning Sciences, 16(4), 523-563. https://doi.org/10.1080/10508400701525238

Novak, E., Razzouk, R., \& Johnson, T. E. (2012). The educational use of social annotation tools in higher education: A literature review. Internet and Higher Education, 15(1), 39-49. https://doi.org/10.1016/j.iheduc.2011.09.002

Pomerantz, J., \& Peek, R. (2016). Fifty shades of open. First Monday, 21(5). https://doi.org/10.5210/fm.v21i5.6360

Roschelle, J., \& Teasley, S. D. (1995). The construction of shared knowledge in collaborative problem solving. In C.E. O’Malley (Ed.), Computer supported collaborative learning (pp. 69-97). Springer.

Saldaña, J. (2016). The coding manual for qualitative researchers (3rd ed.). Sage. https://uk.sagepub.com/en-gb/eur/the-coding-manual-for-qualitativeresearchers/book243616

Shum, S. B., \& Ferguson, R. (2012). Social learning analytics. Journal of Educational Technology \& Society, 15(3), 3-26. https://www.jstor.org/stable/10.2307/jeductechsoci.15.3.3 
Slotta, J. D., \& Najafi, H. (2013). Supporting collaborative knowledge construction with Web 2.0 technologies. In C. Mouza \& N. Lavigne (Eds.), Emerging technologies for the classroom (pp. 93-112). Springer. https://doi.org/10.1007/978-1-4614-4696-5_7

Sprouse, M. (2018). Social annotation and layered readings in composition. In C. Chen, K. Purzycki, \& L. Wilkes (Eds.), The Proceedings of the Annual Computers \& Writing Conference 2018 (pp. 39-52). https://wac.colostate.edu/resources/wac/proceedings/cw2018/

Stagg, A. (2017). The ecology of the open practitioner: A conceptual framework for open research. Open Praxis, 9(4), 363-374. https://doi.org/10.5944/openpraxis.9.4.662

Stahl, G. (2017). Group practices: A new way of viewing CSCL. International Journal of Computer-Supported Collaborative Learning, 12(1), 113-126. https://doi.org/10.1007/s11412-017-9251-0

Suthers, D. D. (2006). Technology affordances for intersubjective meaning making: A research agenda for CSCL. International Journal of Computer-Supported Collaborative Learning, 1(3), 315-337. https://doi.org/10.1007/s11412-006-9660-y

Veletsianos, G., \& Kimmons, R. (2012). Networked participatory scholarship: Emergent technocultural pressures toward open and digital scholarship in online networks. Computers \& Education, 58(2), 766-774. https://doi.org/10.1016/j.compedu.2011.10.001

Weller, M., Jordan, K., DeVries, I., \& Rolfe, V. (2018). Mapping the open education landscape: Citation network analysis of historical open and distance education research. Open Praxis, 10(2), 109-126. https://doi.org/10.5944/openpraxis.10.2.822

Whaley, D. (2017, February 24). Annotation is a now a web standard. https://web.hypothes.is/blog/annotation-is-now-a-web-standard/ 
Winchell, A., Mozer, M., Lan, A., Grimaldi, P., \& Pashler, H. (2018). Can textbook annotations serve as an early predictor of student learning? International Educational Data Mining Society, 431-437. https://eric.ed.gov/?id=ED593211 